\title{
Study of the predominant defect development in rails of underground systems after preventive grinding and lubrication
}

\author{
Serhii Voronin ${ }^{1}$, Oleksii Skoryk ${ }^{2}$, Volodymyr Stefanov ${ }^{1}$, Dmytro Onopreychuk ${ }^{1}$, and Yevhen \\ Korostelov ${ }^{2 *}$ \\ ${ }^{1}$ Ukrainian State University of Railway Transport, Department of Construction, track and handling \\ machines, Feuerbach sq., 7, Kharkov, Ukraine, 61050 \\ ${ }^{2}$ Ukrainian State University of Railway Transport, Department of Track and track facilities, \\ Feuerbach sq., 7, Kharkov, Ukraine, 61050
}

\begin{abstract}
In order to determine the method of contact surface treatment and to define the rational surface roughness in the wheel/rail contact for the minimal growth rate of contact fatigue defects the program of experiments in operational conditions was developed. On the basis of the results and calculations the coefficients of regression equations, which describe dependencies of the wear rate on the parameters of the contact surface treatment in real operational conditions were obtained. Besides, the diagrams of dependencies of the friction coefficient on the roughness of railhead contact surface of the high rails with and without lubrication, when laid in curves of underground systems, were built. The experiments conducted in operational conditions of Kharkiv Metro revealed the influence of roughness of the railhead side surface of the high rails in curves on the contact fatigue defect development after preventive grinding and lubrication. According to the results of the experiments it was established that the rail preventive grinding with simultaneous lubrication led to slower contact fatigue defect development in rails of underground systems. The rational roughness of the railhead side surface of the high rails in curves after preventive grinding, which led to the minimal rate of defect development, was defined.
\end{abstract}

\section{Introduction}

Development of the defect according to figure 11.1-2 [1, 2] as dominant for rails of Kharkiv Metro is a multistage process accompanied by the appearance of nano- and microcracks, propagation of cracks, layer separation and spalling the contact surface material. These effects are of contact fatigue nature. The rate of their development depends on the contact material properties. Taking it into consideration it is possible to slow the defect development in side surfaces of the high rails in curves of underground systems at initial stages.

\footnotetext{
* Corresponding author: dek str@ukr.net
} 
The primary inspection of rails in Kharkiv Metro demonstrated the presence of contact fatigue defects of the «head checking» type indicating, as the authors believe, the initial stage of the defect, according to figure 11.1-2 [2], which appeared due to lack of contact fatigue strength of the rail steel. This may lead to early removal of such rails.

The average life of rails laid in curves of Kharkiv Metro is 1.5-2 years [2], which is too long.

The measures for preventing the mentioned defects include, mostly, slower development of contact fatigue defects at initial stages [1].

\subsection{Analysis of recent studies and publications}

The issue of a low rate of the contact fatigue defect development in the wheel/rail system with consideration of all contact features is not solved so far [3]. Considering differences in contact conditions the issue can be solved for certain contact types [4-6]. The research was mostly conducted with consideration of some contact features with many assumptions.

The analysis of existing ways to decrease the rate of the contact fatigue defect development on the railhead side surface, as the most vulnerable for contact conditions of the wheel/rail system in curves of underground tracks, is presented in [3].

The analysis of previous research has shown that the grinding of the railhead during operation on Ukraine's railways is mostly aimed at shaping the railhead [7]. And the issue of achieving certain characteristics of the microgeometry of contact surfaces and the friction control for slow contact fatigue defect development has not been considered at all. The friction control, however, is the most effective method to decrease the rate of defect progress in rails on tracks of underground systems [3].

Studies [8] define the influence of the traffic speed and roughness of contact surfaces on the stress rate in the wheel/rail contact for main line railways. The research of this kind has not been conducted for underground systems so far.

Article [9] proposes rail grinding for achieving rational characteristics of the microgeometry of contact surfaces. And there is a need to consider the features of contact conditions and the material of contact elements in grinding. This is possible for underground rail systems owing to uniformity of the rolling stock and the track elements.

In [9] for the quarry rail transport in order to increase the friction coefficient in the wheel/rail contact and the running-in speed of contract surfaces, the value of rational roughness of the railhead after grinding was defined. The research was conducted in order to increase the friction coefficient by providing contact surfaces with a certain roughness in difficult conditions of the quarry rail transportation. They cannot be applied for determination of the rational friction coefficient in the wheel/rail contact in curves of underground tracks, though they can indicate the correlation between the roughness of contact surfaces and the friction coefficient.

The research into the influence of parameters of the microgeometry of the wheel/rail contact surfaces by example of the underground system is considered to be promising [1]. In [10] on the friction device for such research the wheel/rail contact along the railhead side surface in a curve in the underground system was simulated. The number of experiments [2] of the influence of the roughness of railhead surfaces of the high rails in curves of underground tracks on the friction force in a simulated wheel/rail contact was conducted. Thus, the rational roughness values of the railhead side surfaces of the high rails in curves of underground tracks were obtained. The results of the bench tests [2] are confirmed by the research in operational conditions on tracks in Kharkiv Metro.

The authors in [11] developed an analytical method of defining the rail life of underground systems with preventive grinding and lubrication on the base of previously conducted bench tests. However the method is applicable only for a dry contact. The application of an analytical method for lubrication conditions is not appropriate considering 
the lubrication film properties. The study presents the research which allows developing the method to define the rail life for underground systems after preventive grinding and lubrication.

\section{The basic part of the study}

The study program in operation conditions of the tracks in Kharkiv Metro included the study on the section Maidan Konstytutsii-Prospekt Haharina. However, considering a large number of contact fatigue defects on this section the authors chose an additional section of similar characteristics on the line Zakhysnykiv Ukrainy-Arkhitektora Beketova, its rail service time being two months.

According to the theoretical and bench tests [2], the range of values of the surface roughness in the wheel/rail contact in curves of underground systems was established and accounted for $R_{a}=4-0^{*} \mu \mathrm{m}$ (* the value of roughness $R_{a}=0.008 \mu \mathrm{m}$ corresponds to the $14^{\text {th }}$ class of roughness by the FEPA standards.) And the contact surfaces were treated with grinding paper of the P150, P320 and P500 granulation.

The values of roughness $R_{a}=0^{*} \mu \mathrm{m}$ was obtained by grinding the contact surfaces. Lubrication of the railhead side surfaces was conducted manually with a lubricant designed for these tests in the laboratory of the Chair «Construction, track and handling machines» Department of Ukrainian State University of Railway Transport [2].

During the experiments in operational conditions, the pictures taken with a digital USBmicroscope were later analyzed in terms of presence of contact fatigue defects and their average size. An average size of contact fatigue defects on the underground section was defined by analyzing the pictures (Fig. 1).

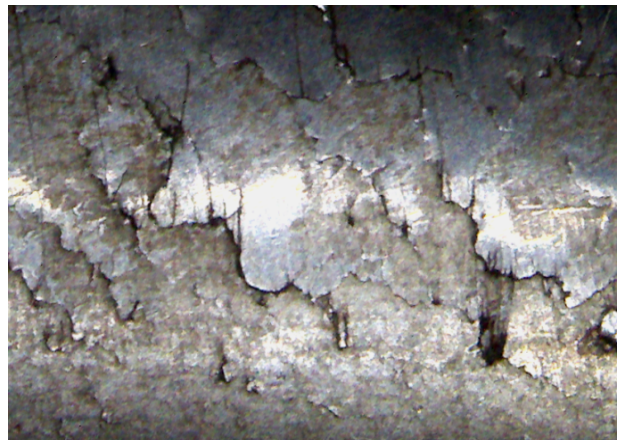

a)

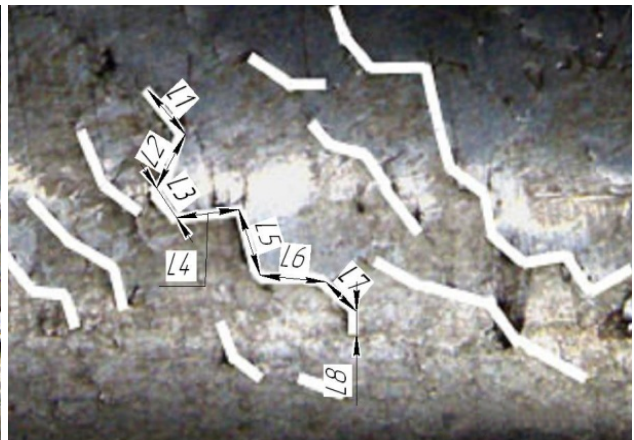

b)

Fig. 1. Determination of the size of contact fatigue defects by analyzing pictures taken by a digital microscope: a) - the picture to be analyzed; b) - the analysis of the picture regarding the average size of the contact fatigue defects; $L_{1}-L_{n}$ - the lengths of the defects

Determination of an average size of the contact fatigue defects on the test sections was made by the formula:

$$
\bar{I}=\frac{\sum_{i=1}^{n} L_{i}}{n}
$$

The research program included two double-factor experiments where the rate of defect development was the response function (Table 1). In order to determine the influence of the rate of the contact fatigue development on the factor of the section tonnage, two doublefactor experiments were conducted, each included ten tests with the frequency equal to two. 
Table 1. Research program in operational conditions

\begin{tabular}{|c|c|c|c|}
\hline $\begin{array}{l}\text { Number of } \\
\text { experiment }\end{array}$ & Lubrication & Roughness & Operation frequency $T$, MT.gross \\
\hline \multirow{5}{*}{1} & \multirow{5}{*}{-} & $R_{a}=4 \mu \mathrm{m}$ & \multirow{10}{*}{1.3} \\
\hline & & $R_{a}=3 \mu \mathrm{m}$ & \\
\hline & & $R_{a}=2 \mu \mathrm{m}$ & \\
\hline & & $R_{a}=1 \mu \mathrm{m}$ & \\
\hline & & $R_{a}=0 * \mu \mathrm{m}$ & \\
\hline \multirow{5}{*}{2} & \multirow{5}{*}{+} & $R_{a}=4 \mu \mathrm{m}$ & \\
\hline & & $R_{a}=3 \mu \mathrm{m}$ & \\
\hline & & $R_{a}=2 \mu \mathrm{m}$ & \\
\hline & & $R_{a}=1 \mu \mathrm{m}$ & \\
\hline & & $R_{a}=0 * \mu \mathrm{m}$ & \\
\hline
\end{tabular}

\section{Results and discussions}

The results of the experiments in operational conditions in Kharkiv Metro are given in Table 2:

Table 2. The results of operational tests on the defect development for the test sections

\begin{tabular}{|c|c|c|c|c|c|c|c|c|c|c|c|c|}
\hline \multirow[b]{2}{*}{ 琣 } & \multirow[b]{2}{*}{ 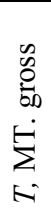 } & \multicolumn{6}{|c|}{ Without lubrication } & \multicolumn{5}{|c|}{ With lubrication } \\
\hline & & $\begin{array}{l}\text { Without } \\
\text { grinding }\end{array}$ & 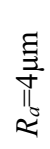 & 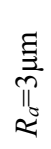 & $\underset{\mathbb{N}}{\mathbb{J}}$ & $\frac{\Xi}{\|_{0}}$ & 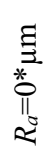 & 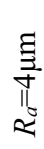 & 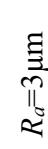 & 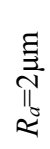 & 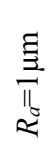 & $\frac{\prod_{\Xi}}{\prod_{0}^{*}}$ \\
\hline
\end{tabular}

An average size of the defect on the section Maidan Konstytutsii-Prospekt Haharina $\bar{I}, \mathrm{~mm}$

\begin{tabular}{|l|l|c|c|c|c|c|c|c|c|c|c|c|}
\hline 1 & 23.4 & 5.500 & 5.500 & 5.500 & 5.500 & 5.500 & 5.500 & 5.500 & 5.500 & 5.500 & 5.500 & 5.500 \\
\hline 2 & 24.7 & 5.963 & 5.954 & 5.948 & 5.940 & 5.956 & 5.959 & 5.910 & 5.903 & 5.894 & 5.913 & 5.915 \\
\hline 3 & 26.0 & 5.651 & 5.620 & 5.723 & 6.574 & 6.630 & 6.633 & 6.502 & 6.497 & 6.458 & 6.518 & 6.525 \\
\hline 4 & 27.3 & 7.462 & 7.392 & 7.405 & 7.309 & 7.421 & 7.428 & 7.190 & 7.154 & 7.110 & 7.227 & 7.230 \\
\hline 5 & 28.6 & 8.364 & 8.245 & 8.193 & 8.120 & 8.299 & 8.312 & 7.949 & 7.855 & 7.827 & 8.012 & 8.223 \\
\hline 6 & 29.9 & 9.340 & 9.164 & 9.003 & 8.992 & 9.248 & 9.264 & 8.765 & 8.612 & 8.596 & 8.859 & 8.870 \\
\hline 7 & 31.2 & 10.380 & 10.138 & 10.062 & 9.915 & 10.257 & 10.295 & 9.630 & 9.621 & 9.410 & 9.760 & 9.893 \\
\hline 8 & 32.5 & 11.474 & 11.161 & 11.013 & 10.883 & 11.320 & 11.403 & 10.538 & 10.293 & 10.263 & 10.707 & 10.801 \\
\hline 9 & 33.8 & 12.622 & 12.228 & 12.173 & 11.893 & 12.431 & 12.442 & 11.485 & 11.164 & 11.151 & 11.696 & 11.706 \\
\hline
\end{tabular}

An average size of the defect on the section Zakhysnykiv Ukrainy-Arkhitektora Beketova $\bar{I}, \mathrm{~mm}$

\begin{tabular}{|l|l|l|l|l|l|l|l|l|l|l|l|l|}
\hline 1 & 2.6 & 0.540 & 0.540 & 0.540 & 0.540 & 0.540 & 0.540 & 0.540 & 0.540 & 0.540 & 0.540 & 0.540 \\
\hline 2 & 3.9 & 0.560 & 0.563 & 0.571 & 0.564 & 0.563 & 0.569 & 0.566 & 0.568 & 0.570 & 0.564 & 0.572 \\
\hline 3 & 5.2 & 0.619 & 0.625 & 0.624 & 0.527 & 0.626 & 0.632 & 0.628 & 0.632 & 0.637 & 0.625 & 0.632 \\
\hline 4 & 6.5 & 0.719 & 0.723 & 0.726 & 0.723 & 0.727 & 0.734 & 0.720 & 0.721 & 0.732 & 0.717 & 0.721 \\
\hline 5 & 7.8 & 0.861 & 0.855 & 0.854 & 0.850 & 0.865 & 0.873 & 0.840 & 0.842 & 0.853 & 0.838 & 0.845 \\
\hline 6 & 9.1 & 1.043 & 1.021 & 1.015 & 1.008 & 1.038 & 1.044 & 0.986 & 0.984 & 0.996 & 0.986 & 0.994 \\
\hline 7 & 10.4 & 1.266 & 1.218 & 1.202 & 1.194 & 1.245 & 1.251 & 1.157 & 1.164 & 1.161 & 1.161 & 1.172 \\
\hline 8 & 11.7 & 1.533 & 1.447 & 1.416 & 1.409 & 1.486 & 1.493 & 1.352 & 1.349 & 1.347 & 1.362 & 1.370 \\
\hline 9 & 13.0 & 1.838 & 1.708 & 1.692 & 1.650 & 1.762 & 1.784 & 1.569 & 1.562 & 1.551 & 1.588 & 1.592 \\
\hline
\end{tabular}

On the basis of the results presented in Table 2, the regression equations describing the development of contact fatigue defects in railhead side surfaces on the test sections of the 
underground railway in dependency on the tonnage carried at various treatments of the contact surface were obtained [11] (Table 3).

Table 3. The regression equations presenting the dependency of the rate of contact fatigue defect development on the surface roughness in the wheel/rail contact in curves of underground systems

\begin{tabular}{|c|c|c|c|}
\hline \multicolumn{2}{|c|}{ Treatment characteristics } & \multirow{2}{*}{$\begin{array}{l}\text { Test section on the line } \\
\text { Maidan Konstytutsii- } \\
\text { Prospekt Haharina }\end{array}$} & \multirow{2}{*}{$\begin{array}{l}\text { Test section on the line } \\
\text { Zakhysnykiv Ukrainy- } \\
\text { Arkhitektora Beketova }\end{array}$} \\
\hline Grinding to & Lubrication & & \\
\hline- & - & $\bar{I}=5.5+0.328 \cdot T^{1.315}$ & $\bar{I}=0.54+0.011 \cdot T^{2.017}$ \\
\hline$R_{a}=4 \mu \mathrm{m}$ & - & $\bar{I}=5.5+0.326 \cdot T^{1.293}$ & $\bar{I}=0.54+0.141 \cdot T^{1.889}$ \\
\hline$R_{a}=4 \mu \mathrm{m}$ & + & $\bar{I}=5.5+0.292 \cdot T^{1.289}$ & $\bar{I}=0.54+0.016 \cdot T^{1.776}$ \\
\hline$R_{a}=3 \mu \mathrm{m}$ & - & $\bar{I}=5.5+0.319 \cdot T^{1.294}$ & $\bar{I}=0.54+0.015 \cdot T^{1.841}$ \\
\hline$R_{a}=3 \mu \mathrm{m}$ & + & $\bar{I}=5.5+0.292 \cdot T^{1.286}$ & $\bar{I}=0.54+0.017 \cdot T^{1.741}$ \\
\hline$R_{a}=2 \mu \mathrm{m}$ & - & $\bar{I}=5.5+0.314 \cdot T^{1.287}$ & $\bar{I}=0.54+0.014 \cdot T^{1.838}$ \\
\hline$R_{a}=2 \mu \mathrm{m}$ & + & $\bar{I}=5.5+0.282 \cdot T^{1.281}$ & $\bar{I}=0.54+0.019 \cdot T^{1.693}$ \\
\hline$R_{a}=1 \mu \mathrm{m}$ & - & $\bar{I}=5.5+0.322 \cdot T^{1.308}$ & $\bar{I}=0.54+0.014 \cdot T^{1.911}$ \\
\hline$R_{a}=1 \mu \mathrm{m}$ & + & $\bar{I}=5.5+0.293 \cdot T^{1.301}$ & $\bar{I}=0.54+0.014 \cdot T^{1.815}$ \\
\hline$R_{a}=0 * \mu \mathrm{m}$ & - & $\bar{I}=5.5+0.333 \cdot T^{1.304}$ & $\bar{I}=0.54+0.013 \cdot T^{1.932}$ \\
\hline$R_{a}=0 * \mu \mathrm{m}$ & + & $\bar{I}=5.5+0.301 \cdot T^{1.318}$ & $\bar{I}=0.54+0.014 \cdot T^{1.838}$ \\
\hline
\end{tabular}

The results of the research in operational conditions can be reproduced in accordance with Cochran's $\mathrm{C}$ test and the models obtained of the rate of contact fatigue defect development in high rail in curves of underground systems proved to be adequate according to the F-test.

By the data given in Table 3 the diagrams of dependency of defect development for the test sections on the tonnage handled are built (Fig. 2-3):

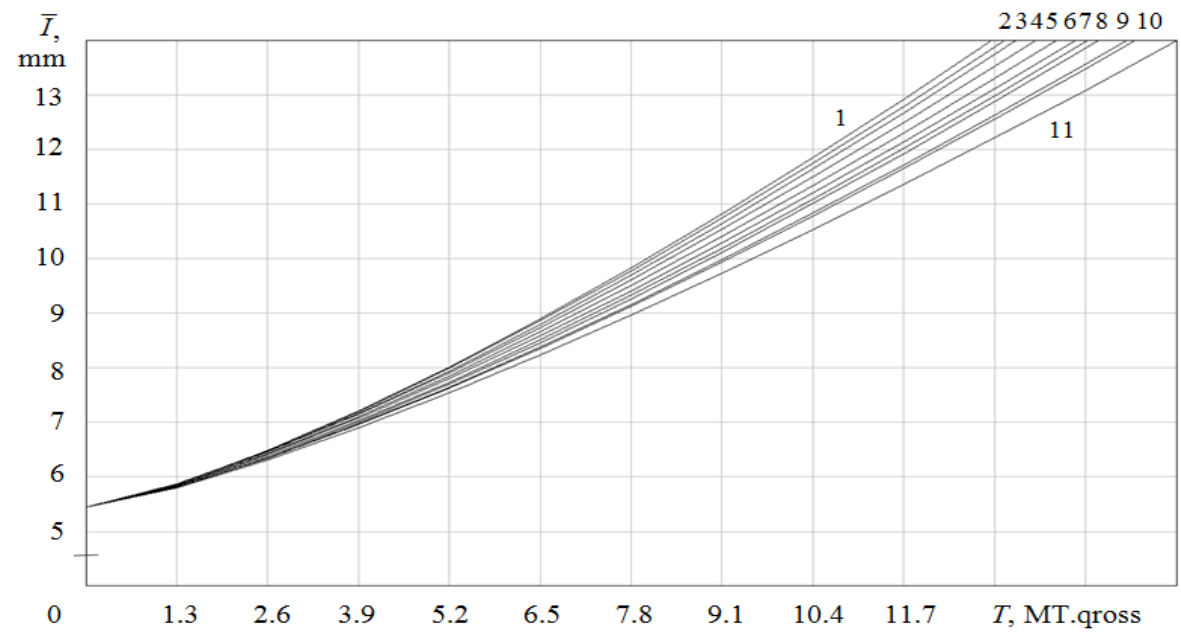

Fig. 2. The dependency of the contact fatigue defect development of the railhead surface of the high rails in curves of underground systems on the tonnage handled for the test section on the line Maidan Konstytutsi-Prospekt Haharina: 1 - without grinding and lubrication; 4, 5, 6, 3, 2 - grinding to $R_{a}=4$, $3,2,1,0^{*} \mu \mathrm{m}$ without lubrication, respectively; $9,10,11,8,7$ - grinding to $R_{a}=4,3,2,1,0^{*} \mu \mathrm{m}$ with lubrication 


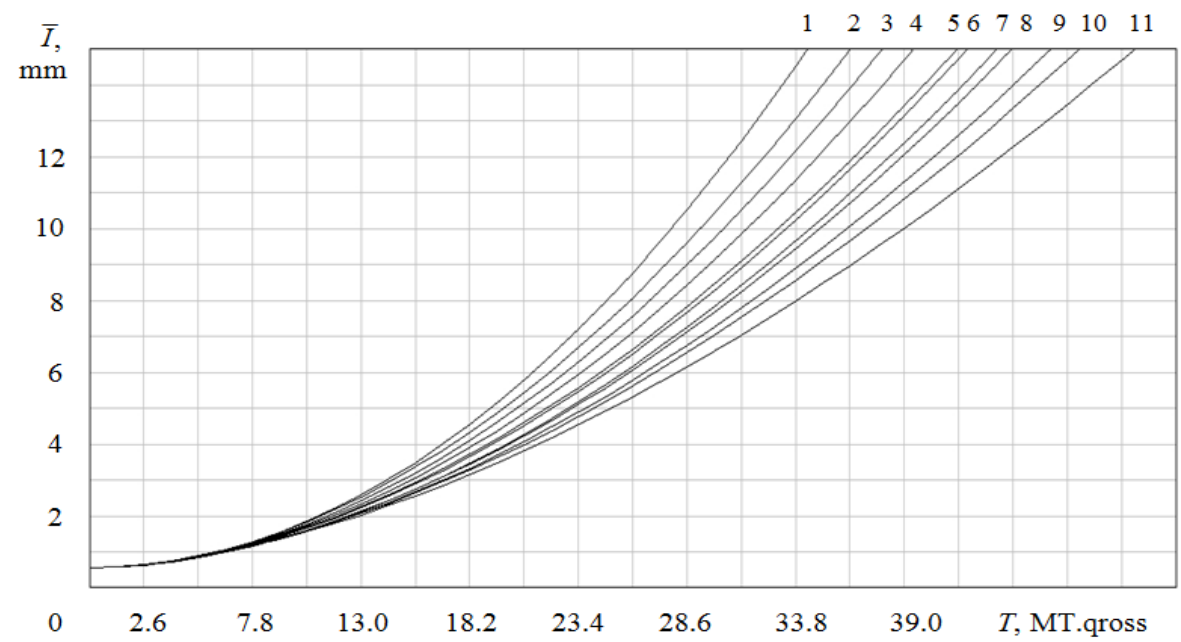

Fig. 3. The dependency of the contact fatigue defect development of the railhead surface of the high rails in curves of underground systems on the tonnage handled for the test section on the line Zakhysnykiv Ukrainy-Arkhitektora Beketova: 1 - without grinding and lubrication; 4, 5, 6, 3, 2 grinding to $R_{a}=4,3,2,1,0^{*} \mu \mathrm{m}$ without lubrication, respectively; $9,10,11,8,7$ - grinding to $R_{a}=4$, $3,2,1,0^{*} \mu \mathrm{m}$ with lubrication

The experiments conducted in operational conditions established that preventive grinding with lubrication led to slow development of contact fatigue defects on railhead side surface of the high rails in curves of underground systems. The values of the rational roughness of railhead side surfaces of the high rails in curves of underground systems after preventive rail grinding of rails with $R_{a}=2 \mu \mathrm{m}$, when contact fatigue defects propagate with the minimal speed, have been established. Besides, the analysis of dependencies presented in Fig. 2-3 demonstrates that the rational solution regarding retardation of the contract fatigue defect development is preventive grinding of railhead side surfaces in curves of underground rail systems with lubrication of the treated surfaces since the beginning of their service.

\section{Conclusion}

In order to determine the method of a contact surface treatment and to define the rational surface roughness in the wheel/rail contact for minimal growth rate of contact fatigue defects the program of experiments in operational conditions was developed.

The research conducted in operational conditions in curves of Kharkiv Metro revealed the influence of the roughness of railhead side surfaces of the high rails in curves after preventive grinding and lubrication on the contact fatigue defect development.

The results of the experiments carried out in the operational conditions made it possible to establish that the rail preventive grinding with simultaneous lubrication led to slower contact fatigue defect development in rails of underground systems. The rational roughness of the railhead side surface of the high rails in curves after preventive rail grinding at $R_{a}=2 \mu \mathrm{m}$ with minimal rate of defect development was defined. And the preventive grinding with consequent lubrication of treated rail surfaces should begin with laying down rails in curves of underground systems.

\section{References}

1. Ye. Korostelov. Nauchnye trudy SWorld. 3 (44), 25-30 (2016). 
2. S. Voronin, O. Skoryk, Ye. Korostelov. Eastern-European Journal of Enterprise Technologies. 4 (80). 11-17 (2016).

3. S. Voronyn, Ye. Korostelov. Informatsiyno-keruyuchi systemy na zaliznychnomu transporti, 3, 22-27 (2014).

4. A. Alonso, J. Gimenez. TRIBOL INT, 8, 755-768 (2008).

5. P. Remington, J. Webb. J. SOUND VIB. 5-6, 83-102 (1996).

6. A. Rovira, A. Roda, M. Marshall, H. Brunskill, R. Lewis. WEAR, 5-6, 911-924 (2011).

7. D. Potapov, V. Vitolberh. Informatsiyno-keruyuchi systemy na zaliznychnomu transporti, 5-6, 70-73 (2006).

8. W. Wang, R. Lewis, B. Yang, L. Guo, Q. Liu, M. Zhu. WEAR, 15, 146-152 (2016).

9. A. Keropyan. Procedia Engineering, 150, 406-410 (2016).

10. S. Voronyn, S. Karpenko, Ye. Korostelov. Zbirnyk nauk. prats UkrDAZT, 148, 201204 (2014).

11. S. Voronin, O. Skoryk, Ye. Korostelov. Zbirnyk nauk. prats UkrDUZT, 167, 156-162 (2017). 